\title{
THE CHALLENGE-BASED LEARNING IN HIGHER EDUCATION THROUGH A CREATIVE SENSORIAL BOOTH TO DISCONNECT AND TO BE HERE NOW
}

\author{
Rubén VÁZQUEZ, Angélica CASTREJÓN, and Alejandro ACUÑA \\ Tecnológico de Monterrey
}

\begin{abstract}
Our senses act as sensors that allow us to receive the information of the reality that we perceive, either in isolation or because of their crossing. During the block's challenge called: Formal Representation of Space (FRS), the aim is for higher education students to enjoy an immersive and experimental experience in understanding space through sensory perceptions, taking the students through its material and virtual representation by drawing techniques, both analogue and virtual; putting into practice themes of geometry, perspective, technologies in art, models, and prototypes. The block is based in Challenged-based learning (CBL) and the challenge in Competency-based learning that "Tec-21" offers to the first year Creative Studies professional students. The group is formed from students of several areas such as Architecture, Industrial Design, Educative Innovation, Hispanic Letters, Journalism, Musical Production, Digital Art, Communication, which lead to conformed multidisciplinary teams. The project consists of designing a Sensorial Booth (SB), an installation that seeks to generate a space in which the perception of the environment can be highlighted through the senses in a playful and interactive way. The main objective is to involve the students in a real challenge while acquiring knowledge through a creative project, as well as interacting with a real space of a real institution, which is one of the main purposes of the CBL. Beyond the creative experience that led to the process of conceptualization and materialization 1:1 scale of the Sensorial Booth, prior to confinement by COVID-19, the students realized the importance of giving a comprehensive and memorable sensory experience to people without the need to be connected to a device, while immersing in the reflection of reconnecting with themselves and with the natural environment that surrounded this installation. Regarding to the learning experience, the students enjoyed the challenged offered by the Educational Innovation programme, Block Tec21, doing the most they enjoy, creating, using technology, working with real materials, and collaborating with real former partners.
\end{abstract}

Keywords: Competencies-based learning, challenge-based learning, Bloque Tec21, educational innovation, higher education

\section{INTRODUCTION}

The CBL implemented in higher education by Tec de Monterrey since 2019 in the so-called Tec 21 system has brought great results in Creative Studies [1]. This innovative educational system seeks to bring theory to practice while developing challenging projects for students and face real-world problems in their learning [2]. In this way, the professor who used to be the centre of attention in the classroom becomes the student's guide and mentor in a new ecosystem learning stage. The main task is that the student can selfmanage time and knowledge. Based on disciplinary and transversal competences, the project the student develops is linked to a training partner, the Labyrinth Museum of Sciences and Arts of San Luis Potosí in México, to reach common objectives, which add both to the student's knowledge and to the goals of the training partner. In this way, the student achieves a certain level of experience in a real context, which is the main objective of the CBL [3], [4]. 
In the first period of the second semester of the Creative Studies entry, from February to March 2020, within the FRS Block, the challenge consisted in designing a Sensorial Booth, in collaboration with the cited training partner, an institution that served as the exhibition space for the physical installation of the pieces developed. It was started from the premise: What if the reality that surrounds us did not exist, or not as we see it? The main objective was for the students to have an immersive and experimental experience in understanding space through sensorial perceptions and their graphic, virtual, and material representation. Thus, while the students review conceptual artists work and approach to postulates of designers and architects to support the conceptual proposal, they made their first sketches individually, and later, as a multidisciplinary team, to arrive at a common proposal. In parallel, inspiration was taken from Bruno Munari's methodology [5] to order their ideas in the design process. Finally, in a collaborative way, the complete project of the Sensorial Booth was carried out, two-dimensionally and threedimensionally, a model was made and the 1:1 scale model was built.

\section{METHODOLOGY}

The five-week design process is made up of five phases, one per week. It begins with the immersion phase, reading about space topics and reviewing the work of conceptual artists; then comes, the inspiration phase, making mood boards and collages; next, the ideation phase arrives, sketching the main ideas; to follow with implementation phase, taking the proposal to plans; to reach the last one, the delivery of the challenge, manufacturing the Sensorial Booth 1:1. This final stage included the construction of the booth on campus, where sensorial and resistance tests were carried out, and later, the collective installation was carried out in situ, in outdoor spaces open to the entire public of the Labyrinth Museum. It is important to say that students were asked to work mainly with natural materials as wood and natural fabrics to connect with the natural environment around the site. Although the subsequent monitoring of the challenge, which consisted of observing and recording the interaction of the booth with the user, was not carried out, due to the COVID-19 pandemic, the students had a stage of intense immersive knowledge, both in the campus workshops as in meetings with the museum curators, which left them an invaluable experience and learning, which in the previous educational system would not have been achieved. The group of 26 students was organized into six multidisciplinary teams who worked the five weeks on campus, where they began to think up and finish their proposal. During the first week, a visit to the museum was made so that students could explore the environment and therefore, plan their installation. Days prior to the final delivery they had an evaluation in the presence of the training partner and finally the assembly of the six rooms was carried out on Thursday, March 12, which was complemented with an identification card and a $\mathrm{QR}$ code that led to the link of a video that showed the creative process.

\subsection{Modules}

\subsubsection{Form and Space}

This module offers as a basis the understanding and organization of spaces; the title of Form, space, and order by Francis Ching [6], was followed for this purpose, giving a basic structure for the creation of the living spaces through design fundamentals. In parallel, students follow readings by authors who address phenomenology of space, such as Peter Zumthor [7], Steven Holl [8] and Juhani Pallasmaa [9], to sensitize students on the subject. Students also review architectural works related with authors such as Tadao Ando and Luis Barragan, to observe the way in which they handle emotions, environment, colours, textures, the play of light and shadow, in other aspects.

\subsubsection{Visual Communication}

The purpose of this module is for the student to recognize the space through freehand and drawing, to learn to represent several materials and settings through various techniques (markers, colours, pencils, etc.) to help them to express spaces, objects, settings, especially ideas that trigger the development of the challenge. In addition, different drawing languages of the architectural world are explored, such as representation of plants, elevations, isometrics, or perspective (sketch-like schematics) using line quality. 
The goal of the module is to emphasize in the student that freehand drawing contributes to reinforcing critical and creative thinking, due to the direct connection that the hand has with the brain.

\subsubsection{Technologies in Art}

In this module, which begins in the third week of the block, the students are prepared to develop skills in 3D modelling for the visual representation of their proposal for a sensory room. There is access to the computer labs of the San Luis Potosí campus, where the software used was Rhinoceros 6 for the virtual model and, Keyshot for the render generation. The campus also has Adobe Photoshop and Illustrator licenses for the generation of photomontages and presentation sheets. This module takes two weeks in which the students develop, first individually and then as a team, the final proposal of their Sensorial Booth. The intention of this module is to generate a preview of the finished project, as well as its materials and context.

\subsubsection{Materialization}

The objective of this module consists of two phases, first, to generate a volumetric model of the individual proposal, while the 3D model is generated in the module explained above. This tells us that both modules are carried out simultaneously. It is important to clear out that, in the second phase, once the teams are formed, a proposal is chosen, the one that best meets the requirements and parameters of the project. Once this is done, a detailed 1: 5 scale model is developed with apparent materials and setting, meanwhile, the digital 3D model starts to take form.

\subsection{Competencies}

This section explains the skills to be developed in this block:

Design of creative proposals: Based on the analysis of the social, cultural and arts context. Create proposals using methodologies based on creative iterative processes.

Meaningful representation: Design solutions based on significant intentionality using visualization and materialization techniques. It interprets the conceptual, virtual, and physical environment as the basis for its proposals. Represents design proposals with relevant physical and digital models and prototypes to deliver a message.

Technologies in art: Integrate innovative tools in an experimental way in the design and production of creative projects. It also identifies suitable analogue and digital devices to its experiment and application. Communication: Uses different languages, resources, and strategies effectively and according to the context, in their interaction in different professional and personal networks with different purposes. Agreements and proposals through the exchange of arguments and emotions, both in the mother tongue and in an additional language, which consider geopolitical and sociocultural contexts.

\subsection{Challenge}

The goal of the challenge is to bridge the gap between thinking and doing. CBL grabs theory into practice, so the learning experience, where the learning takes places through the identification, analysis, and design of a solution to a sociotechnical problem [2], is the main value of this model. In this sense, the premise is the way in which the students carry out the challenge, build the concept, support the idea, and translate it into the construction of a sensory booth to be used freely by de audience of the Labyrinth, to interact with the space, to disconnect of the "real world", to reconnect with themselves and nature and, to feel and explore with all the senses. However, as mentioned before, it was not possible to have feedback because of the pandemic; this also resulted in the reduce exposure time of the booths to only one week, from two that had been contemplated in the beginning.

\section{DISCUSSION \& RESULTS}

Carrying out this project in five weeks, from concept to practice, involves an accelerated learning curve for students, both in terms of conceptualization, visual representation, virtual modelling, and development of functional models and prototypes [10]. On the other hand, what other software would be recommended so that students could generate their 3D models? Not all campuses have an active Rhino or Keyshot 
license, much less the Adobe suite. They could be considered free software, which does not require a license, such as SketchUp in the 3D modelling theme, Blender as the rendering engine and Figma in the vector theme.

The students had a pre-delivery session, where the Directors of the museum set the final recommendations for the final presentation and installation assembly. In this meeting the 1:1 construction of the sensorial booth was approved. Students were asked for a detailed list of materials, suppliers, and costs, to give continuity to the proposal previously reviewed and approved with the mock-up and 3D model. The personnel of the museum had to review the material list and check the stability of the final structures for security, both for the audience and for the institution. Once the rooms were assembled, they were presented on campus in front of external advisers for their final review and assessment. (to later request support for transportation to the Labyrinth, where all the assembly logistics for the pieces have already been planned.) (no se tenga caso poner esta última frase, mejor hablar del proceso de assessment).
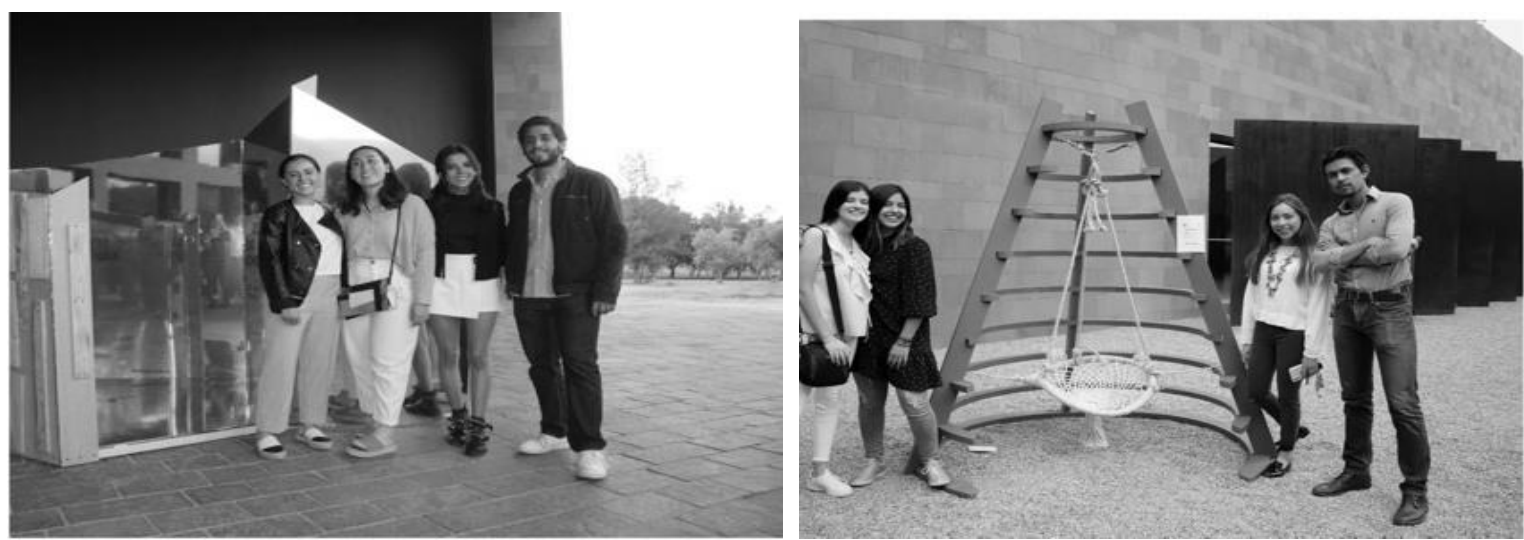

Figure 1. Sensorial booths scale 1:1 installed at the Labyrinth Museum ("Refleja" and "Nido Invertido")
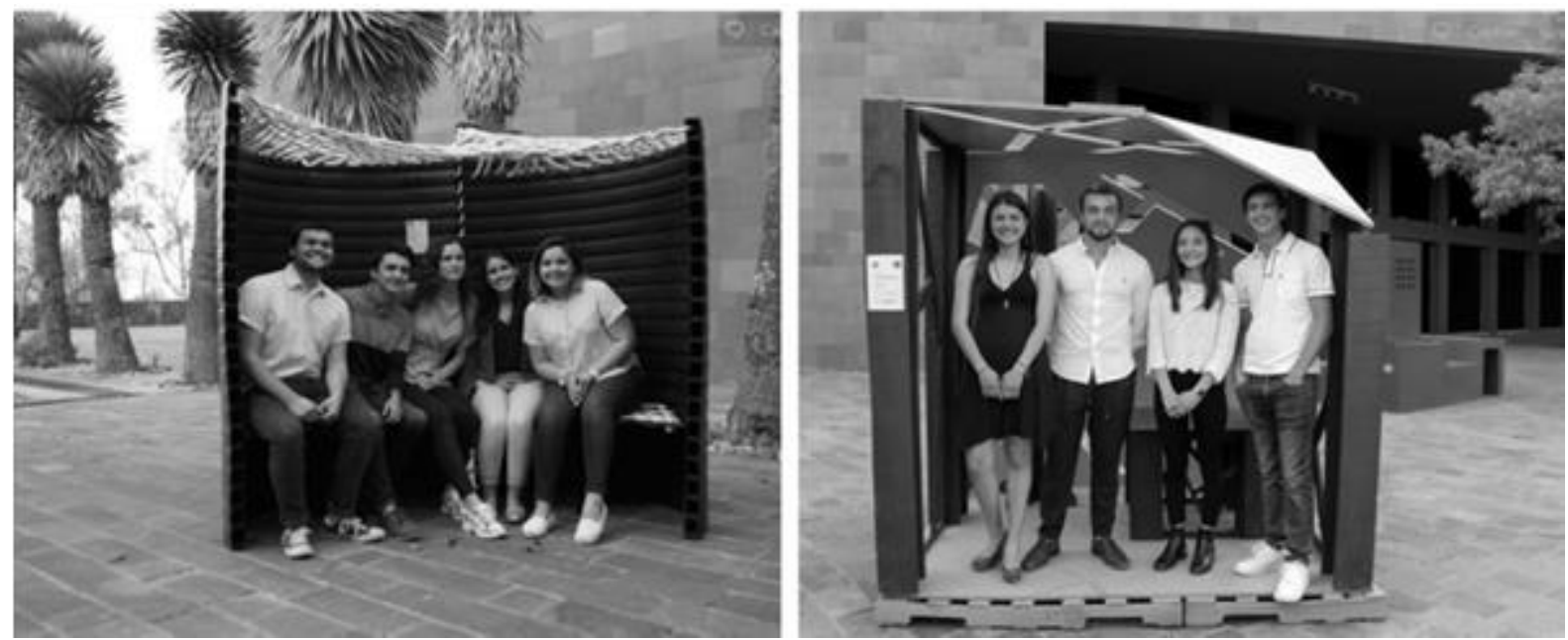

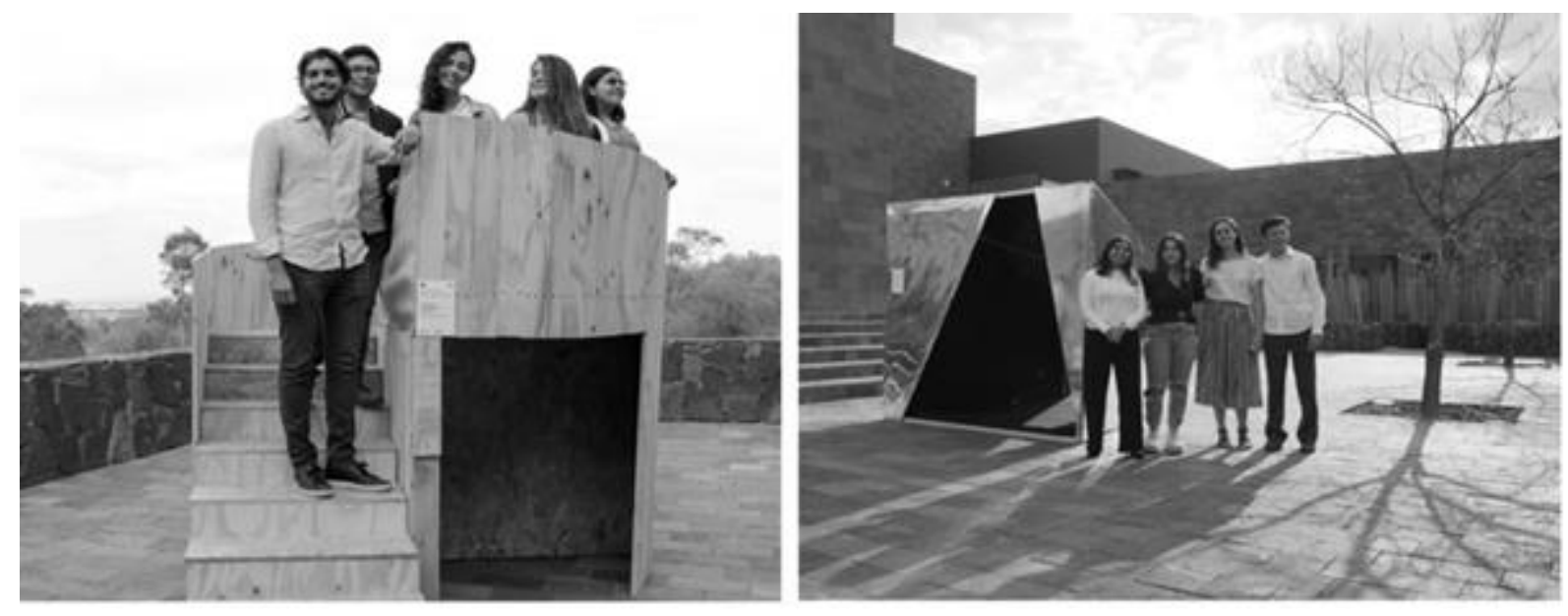

Figure 2. Sensorial booths scale 1:1 installed at the Labyrinth Museum ("Eco", "Biomímesis", "Alighieri", "La Cueva").

\section{CONCLUSIONS}

CBL is a way to give continuity to the creative process, since objectives and achievements are set together with a training partner, who reinforces the commitment of the students. Transversal skills and competencies, such as collaboration and innovation were reinforced by the challenge. Nevertheless, having different modules and phases, its continuity must be constantly reviewed to be within the established times. This part can be seen reflected in the evolution of the proposals, from the exploration of the form and its relationship with the solution of the problem raised, to the technical feasibility and assembly aspects to be considered for the final proposal. It is, in this last phase, where students put into practice the adaptability of their proposal, which should have considered dimensions that can be managed by them and their transportation and economic possibilities available in the city. This project brings students closer to contemplating all the phases and technical implications of a design and construction project, contemplating the concept and the message it seeks to convey, always being an approach to highlighting the importance of appropriating the space that surrounds us and adapting it to the solution of our needs and the way in which they are evolving.

\section{ACKNOWLEDGEMENT}

The authors would like to acknowledge the financial support of Writing Lab, Institute for the Future of Education, Tecnologico de Monterrey, Mexico, in the production of this work.

\section{REFERENCES}

[1] Vázquez Esquivel R., Acuña López A., Ramirez F., Álvarez Tostado M. and Zarate S. Competencybased Evaluation for Creative and Experimental Immersion Challenge. Proceedings of the 22nd International Conference on Engineering and Product Design Education, 2020, https://doi.org/10.35199/epde.2020.60.

[2] Gallagher S. E. and Savage T. Challenge-based learning in higher education: an exploratory literature review, 2020 (School of Computer Science and Statistics, The University of Dublin, Trinity College, Dublin, Ireland).

[3] Torres-Barreto M. L., Castro G. P., and Alvarez M. A Learning Model Proposal Focused on Challenge-Based Learning. AEE Journal, 2020, 8(2), 1-23. https://doi.org/10.18260/3-1-1153-36023

[4] Terradellas M. R. Aprendizaje basado en retos y procesos co-creativos. Una oportunidad para abordar la diversidad familiar y los estereotipos de género en la formación inicial de maestros de educación infantil. Ciencia, Técnica y Mainstreaming Social, 2020, (4), 49. https://doi.org/10.4995/citecma.2020.13408

[5] Ching F. D. K. Architecture: Form, space, \& order. 2007. (John Wiley \& Sons).

[6] Zumthor P. Thinking Architecture, 2006 (Birkhäuser). 
[7] Holl S. and Rodríguez P. M. Cuestiones de percepción: Fenomenología de la arquitectura, 2014. (Editorial Gustavo Gili).

[8] Pallasmaa J. Los ojos de la piel: La arquitectura y los sentidos, 2014. (Editorial Gustavo Gili).

[9] Hercz M., Pozsonyi F. and Flick-Takács, N. Supporting a Sustainable Way of Life-Long Learning in the rame of Challenge-Based Learning. Discourse and Communication for Sustainable Education, 2020, 11(2), 45-64. https://doi.org/10.2478/dcse-2020-0018 